\title{
Revised Shock-Wave Equations of State for High-Pressure Phases of Rocks and Minerals ${ }^{1}$
}

\author{
Geoffrey F. Davies and Don L. Anderson \\ Seismological Laboratory, California Institute of Technology, Pasadena 91109
}

\begin{abstract}
Shock-wave data for the high-pressure phases of a number of rocks and minerals have been reanalyzed using a revised seismic equation of state to constrain the zero-pressure properties of the high-pressure phases. The anomalously low values of $d K / d P$ resulting from a previous analysis are thereby removed. The inferred zero-pressure densities of the high-pressure phases are reduced by an average of $4 \%$, and the values of the zero-pressure seismic parameter $\Phi_{0}$ are reduced by up to $30 \%$, bringing them into approximate agreement with the hypothesis of the molar additivity of $\Phi$. For most of the materials considered, the derived pressure trajectories of density versus the seismic parameter $\Phi$ are consistent wth shock-wave data on such materials as $\mathrm{MgO}, \mathrm{Al}_{2} \mathrm{O}_{3}$, and $\mathrm{SiO}_{2}$ (stishovite) where no zero-pressure assumptions are required. Iron-rich compounds may require further revision. It is demonstrated that in poorly constrained cases the Birch-Murnaghan equation can produce a singularity in $d K / d P$ at high pressure. Possible crystal structures of the high-pressure phases are considered using the revised zero-pressure densities. It seems likely that olivines with less than about 10-mole \% $\mathrm{FeO}$ content can transform to a phase significantly denser than the isochemical mixture of oxides, in contrast to olivines with higher iron content. The possibility that electron spin transitions occur in iron-rich compounds is considered, but no strong evidence has been obtained. The derived zero-pressure densities of the high-pressure phases are usually not of sufficient accuracy to distinguish between all alternative structures, but in some cases an alternative structure to that previously chosen is preferred here.
\end{abstract}

Our knowledge of the properties of rocks and minerals at the temperatures and pressures of the lower mantle depends heavily on the results of shock-wave experiments. The reduction of shock-wave results to quantities that can be compared to known properties of the lower mantle is complicated because most of the minerals likely to be important constituents of the mantle undergo phase transformations under high pressure. In most cases the crystal structure of the high-pressure phase is unknown. Several recent papers have employed various assumptions about the zero-pressure properties of the high-pressure phases in order to derive appropriate pressure-density relations for these phases [e.g., Wang, 1968; D. L. Anderson and Kanamori, 1968; Ahrens et al., 1969]. In this paper we have used for this purpose a revised form of the seismic equation

\footnotetext{
1 Contribution 1906, Division of Geological Sciences, California Institute of Technology, Pasadena, California 91109.
}

Copyright (c) 1971 by the American Geophysical Union. of state [D. L. Anderson, 1967, 1969] that is more appropriate to the close-packed crystal structures to be expected at high pressures. Other forms of this equation were used by D. L. Anderson and Kanamori [1968] and Ahrens et al. [1969]. We will show that the revised seismic equation of state yields highpressure behavior that is physically more reasonable than that yielded by previous forms.

Specifically, use of the revised seismic equation of state removes anomalously low values of $K_{s}^{\prime}=\left(d K_{s} / d P\right)_{s}$ at high pressures that resulted from the analysis by Ahrens et al. [1969]. (Here $K$ is the bulk modulus, $P$ is pressure, and subscript $S$ denotes constant entropy.) It also reduces the inferred zero-pressure densities of the high-pressure phases by a few percent, and reduces by $20 \%$ or more the zero-pressure value $\Phi_{0}$ of the seismic parameter $\Phi=K / \rho$, where $\rho$ is density. The resulting values of $\Phi_{0}$ are shown to agree approximately with values predicted by the hypothesis of the molar additivity of $\Phi$ of the component oxides proposed by $D . L$. Ander$\operatorname{son}[1969]$.

It is demonstrated that in extreme cases the 
Birch-Murnaghan equation can cause a singularity in $d K / d P$ at high pressure, and that it must therefore be applied with caution when there is a lot of uncertainty in the parameters of the equation, or when extrapolation to very high pressures is desired.

Possible crystal structures of the high-pressure phases of shocked minerals and rocks were discussed by Ahrens et al. [1969] on the basis of the derived zero-pressure densities. These are reconsidered here using the new zero-pressure densities. In many cases the same structure still seems appropriate. The possibility that, in some of the iron-rich compounds, the $\mathrm{Fe}$ ions have undergone high-spin to low-spin transitions is investigated, but no clear evidence of this transition is obtained.

We have considered shock-wave data of the 17 rocks and minerals previously studied by Ahrens et al. [1970], and the 2 diabases discussed by D. L. Anderson and Kanamori [1968]. The original data are from McQueen, Marsh, and Fritz (unpublished), Wackerle [1962], Al'tshuler et al. [1965], and Trunin et al. [1965]. Some of the data of McQueen et al. have been published by McQueen et al. [1967] and by Birch in Clark [1966].

\section{Method of ANalysis of Shock-Wave Data}

The procedure used here for the reduction of shock-wave hugoniot data to appropriate adiabats is essentially the same as that described by Ahrens et al. [1969]. All pressure-density curves (Hugoniots and adiabats) have been approximated by the Birch-Murnaghan equation

$$
P=1.5 K_{0}\left(x^{7}-x^{5}\right)\left[1-\xi\left(x^{2}-1\right)\right]
$$

where $x=\left(\rho / \rho_{0}\right)^{1 / 3}, \rho_{0}$ is the zero-pressure density, $K_{0}$ is the zero-pressure bulk modulus, and $\xi$ is a parameter related to the pressure derivative of the bulk modulus at zero pressure by

$$
(\partial K / \partial P)_{P \sim 0}=K_{0}^{\prime}=4-(4 / 3) \xi
$$

It has been argued recently [Thomsen, 1970] that alternative equations to the Birch-Murnaghan equation can be derived either by including higher order terms, or by using alternative definitions of strain. An indication of the effect of changing the form of the pressure-density relation can be obtained from the results of D. L. Anderson and Kanamori [1968], who reduced the raw Hugoniot data of a number of materials using both the Birch-Murnaghan equation and the Murnaghan equation. Their results indicate that use of the Murnaghan equation would increase the zero-pressure densities obtained here by less than $1 \%$, that $\Phi_{0}$ would change by less than about $4 \%$, and that $\Phi$ at a pressure of $1 \mathrm{mb}$ would be changed by less than $10 \%$. These effects would not change the conclusions of this paper.

The Grüneisen ratio $\gamma$ has been calculated from the Dugdale-Macdonald formula

$$
\gamma=-\frac{V}{2} \frac{d^{2}\left(P V^{2 / 3}\right) / d V^{2}}{d\left(P V^{2 / 3}\right) / d V}-\frac{1}{3}
$$

where $V=1 / \rho$ is the specific volume, and the derivatives are taken at $0^{\circ} \mathrm{K}$. If the $0^{\circ} \mathrm{K}$ isotherm is assumed to have the Birch-Murnaghan form (1), then

$$
\gamma=\frac{\left(5 x^{2}-2\right)-(1 / 3) \xi_{T}\left(28 x^{4}-30 x^{2}+6\right)}{\left(5 x^{2}-3\right)-\xi_{T}\left(7 x^{2}-3\right)\left(x^{2}-1\right)}
$$

where $\xi_{T}$ is the parameter of the $0^{\circ} \mathrm{K}$ isotherm. An excellent approximation to $\xi_{r}$ is $\xi_{s}$, the parameter of the adiabat centered at $300^{\circ} \mathrm{K}$ and $P=0$, so it is therefore not necessary to calculate the $0^{\circ} \mathrm{K}$ isotherm. Nevertheless, an iterative scheme must be used to simultaneously calculate $\gamma$ and the 'room temperature' adiabat from the shock-wave data, since they are interdependent.

Fortunately, the rather crude assumptions that we are forced to make about $\gamma$ do not materially affect the conclusions about the zeropressure densities of the high-pressure phases. The main constraints on the present problem are the shock-wave data and the choice of the seismic equation of state parameters. For example, Ahrens et al. [1969, Table 9] assumed various zero-pressure values of $\gamma$, and tested both $\gamma=$ constant and $\gamma / V=$ constant. For the present study, the additional laws $\gamma / V^{2}=$ constant and $\gamma / V^{s}=$ constant were tested. Through all of these cases the variation of $\rho_{0}$ was less than $1 \%$, the variation of $\Phi_{0}$ about $2 \%$, and the variation of $\Phi$ at $1-\mathrm{mb}$ pressure about $10 \%$. These variations are significantly less than the effects of the revision of the seismic equation of state to be presented here. 
The seismic equation of state used by Ahrens et al. [1969] to constrain the zero-pressure properties of the high-pressure phases was

$$
\rho_{n}=0.048\langle M\rangle \Phi_{\mathrm{n}}{ }^{0.323}
$$

This resulted from fitting the zero-pressure properties of a selection of 31 rocks and minerals, which included many with open crystal structures such as $\alpha$-quartz and feldspars [D. $L$. Anderson, 1967]. It was pointed out by $D$. $L$. Anderson [1969] that the equation

$$
\rho_{0}=0.0492\langle M\rangle \Phi_{0}{ }^{1 / 3}
$$

gave a good fit to the zero-pressure properties of $\mathrm{MgO}, \mathrm{Al}_{2} \mathrm{O}_{3}$, and $\mathrm{SiO}_{2}$ (stishovite), all of which have close-packed crystal structures. Equation 6 thus seems more appropriate to describe the zero-pressure properties of the close-packed phases to be expected in the lower mantle. The results presented here support this conjecture.

\section{Comparison of Results using Old and New Seismic Equations of State}

The results of the analysis of the shock-wave data when the original (equation 5) and revised (equation 6) equations of state are used are given in Table 1 and Figures 1 and 2. Table 1 lists the Birch-Murnaghan parameters $\rho, K_{\text {" }}$, and $\xi$ of the 'ambient' adiabat (i.e., centered at $300^{\circ} \mathrm{K}$ and $P=0$ ) of each material considered. Also listed are $K_{0}^{\prime}$, from (2), and $\Phi_{0}$, the zeropressure value of the seismic parameter $\Phi_{0}=$ $(\partial P / \partial \rho)_{s}=K_{s} / \rho$, where the subscript $S$ indicates constant entropy.

The difference between the original and re-

\begin{tabular}{|c|c|c|c|c|c|c|c|c|c|c|}
\hline & \multicolumn{5}{|c|}{$\rho_{0}=0.048(M) \Phi^{0.828}$} & \multicolumn{5}{|c|}{$\rho_{0}=00492\langle M\rangle \Phi^{1 / 3}$} \\
\hline & $\stackrel{\rho 0}{\rho,}$ & $\begin{array}{l}K_{0} \\
\mathrm{Mb}\end{array}$ & $\boldsymbol{\xi}$ & $K_{0^{\prime}}$ & $\begin{array}{c}\Phi_{0,} \\
(\mathbf{k m} / \mathrm{sec})^{2}\end{array}$ & $\begin{array}{l}\rho 0 \\
\mathrm{~g} / \mathrm{cm}\end{array}$ & $\begin{array}{l}K_{0} \\
(\mathbf{M b})\end{array}$ & $\xi$ & $K_{0^{\prime}}$ & $\begin{array}{c}\Phi_{0,} \\
(\mathrm{~km} / \mathrm{sec})^{2}\end{array}$ \\
\hline Forgterite (Fo) & 4.31 & 4425 & 222 & 1.05 & 103 & 4.18 & 3.186 & 0.88 & 283 & 76 \\
\hline Olivinite I (Oliv) & 458 & 4840 & 0.86 & 285 & 106 & 428 & 2961 & 048 & 335 & 69 \\
\hline Twin Sisters dunite (TS) & 4.12 & 3367 & 1.01 & 2.65 & 82 & 394 & 2.147 & 0.41 & 3.45 & 55 \\
\hline Hortonolite dunite (Ho) & 4.75 & 3319 & 122 & 2.37 & 70 & 4.59 & 2.366 & 0.65 & 3.14 & 52 \\
\hline Fayalite (Fa) & 531 & 3.319 & 187 & 150 & 63 & 503 & 2.173 & 0 89 & 281 & 43 \\
\hline Hematite $\left(\mathrm{Fe}_{2} \mathrm{O}_{3}\right)$ & 5.96 & 3991 & 152 & 1.98 & 67 & 570 & 2.727 & 0.83 & 289 & 48 \\
\hline Magnetite $\left(\mathrm{Fes}_{4}\right)$ & 630 & 4488 & 1.66 & 1.79 & 71 & 6.11 & 3225 & 094 & 274 & $\mathbf{5 3}$ \\
\hline Spinel (Sp) & 419 & 3819 & 106 & 259 & 91 & 403 & 2646 & 053 & 329 & 65 \\
\hline Enstatite (Ens) & 420 & 4031 & 423 & -1.64 & 96 & $393 e$ & $\cdots$ & $\cdots$ & $\cdots$ & $\cdots$ \\
\hline Bronzitite (Br) & 374 & 2117 & 1.14 & 2.48 & 57 & $3 \mathbf{3 3}$ & 1086 & 0.49 & 334 & 33 \\
\hline Sillimanite (Sill) & 400 & 3.187 & 1.40 & 2.33 & 80 & 394 & 2435 & 082 & 2.91 & 62 \\
\hline Andalusite (And) & 395 & 3045 & 116 & 2.46 & 77 & 384 & 2185 & 0.61 & 3.19 & 57 \\
\hline Anorthosite (An) & 3.71 & 2084 & 1.20 & 2.40 & 56 & 3.57 & 1481 & 067 & 311 & 41 \\
\hline Oligoclase (Olig) & 369 & 2.198 & 1.60 & 1.87 & 60 & 3.57 & 1592 & 072 & 3.15 & 45 \\
\hline Albitite (Alb) & 381 & 2550 & 1.63 & 182 & 67 & 3.69 & 1.84 & 0.71 & 3.05 & 50 \\
\hline Microcline (Mier) & 350 & 1563 & 1.47 & 204 & 45 & 3.36 & 109 & 070 & 3.06 & 33 \\
\hline Westerly granite (WGr) & 3.96 & 2.907 & 1.32 & 224 & 73 & 3.90 & 222 & 0.75 & 3.00 & 57 \\
\hline Eclogite (Ecl) & 3.61 & 1.555 & 0.76 & 299 & 43 & 349 & 112 & 039 & 348 & 32 \\
\hline Periclase (MgO) & $3584 a$ & 1628 & 011 & 3.85 & 45 & & & & & \\
\hline Corundum $\left(\mathrm{Al}_{2} \mathrm{O}_{2}\right)$ & $3988 a$ & 2551 & -0.12 & 416 & 64 & & & & & \\
\hline Stishovite $\left(\mathrm{SiO}_{2}\right)$ & $4287^{a}$ & 3546 & 066 & 3.12 & 83 & & & & & \\
\hline Wustite $(\mathrm{FeO})$ & $586^{a, b}$ & $\cdots$ & $\cdots$ & $\cdots$ & $30^{6}$ & & & & & \\
\hline \multicolumn{11}{|c|}{ 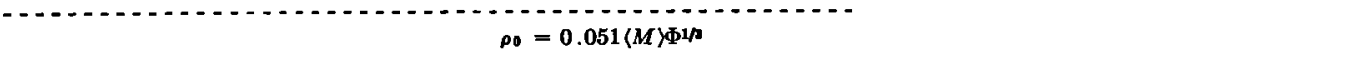 } \\
\hline Fayalite & 482 & 1.65 & 067 & 310 & 34 & & & & & \\
\hline Hematite & 5.44 & 203 & 058 & 323 & 37 & & & & & \\
\hline Magnetite & 6.00 & 2.69 & 072 & 3.05 & 45 & & & & & \\
\hline
\end{tabular}

TABLE 1. Parameters of the Ambient Adiabats Derived Using the Original and Revised Seismic Equatione of State

a Fixed density.

b Extrapolated from Fe.96 [Clark, 1966; D. L. Anderson, 1969].

- From hugoniot. 
vised results is most strikingly illustrated by Figures 1 and 2. In these figures, the loci of the ambient adiabats have been plotted in the $\log (\rho /\langle M\rangle)-\log \Phi$ plane (note that $\langle M\rangle / \rho$ is the molar volume). In this plane the seismic equations of state (5) and (6) are straight lines (of slopes 0.323 and $1 / 3$, respectively). The zero-pressure ends of the adiabatic curves all fall on the seismic equation of state line, with pressure increasing away from the line along each adiabat. It can be seen that the original adiabats in Figure 1 are much less orderly than the revised adiabats in Figure 2, and that for many of the original adiabats $\Phi$ becomes a decreasing function of $\rho$ (and $P$ ) at higher pressures, whereas this does not occur in Figure 2.

From the definitions $K=\rho d P / d \rho$ and $\Phi=$ $K / \rho$, it can readily be shown that for any given function $P=P(\rho)$.

$$
\frac{d(\log \Phi)}{d(\log \rho)}=\frac{d K}{d P}-1
$$

Thus a slope of $1 / 3$ in the $\log (\rho /\langle M\rangle)-\log \Phi$ plane corresponds to $d K / d P=4$, and a slope of -1 corresponds to $d K / d P=0$. The theoretical high-pressure limit on $d K / d P$, as given by the Thomas-Fermi approximation, is $5 / 3$ [March, 1955], which corresponds to a slope of $3 / 2$ in Figures 1 and 2. (Lines of slope 1/3, 3/2, and -1 are shown in Figure 1 for comparison.) Clearly, for many of the original adiabats (Figure 1) $d K / d P$ falls below the Thomas-Fermi limit at high pressures, and for some it falls below zero. For the revised adiabats (Figure 2), $d K / d P$ approaches the Thomas-Fermi limit at high pressures in some cases, but usually is substantially greater.

The revision has had the additional effect that at all pressures the range of values of $d K / d P$ for the substances considered is much narrower. This narrow range is illustrated by the range of slopes of the adiabats in Figure 1 as compared to Figure 2, and also, at zero pressure, by the values of $K_{0}^{\prime}$ given in Table 1 . The original

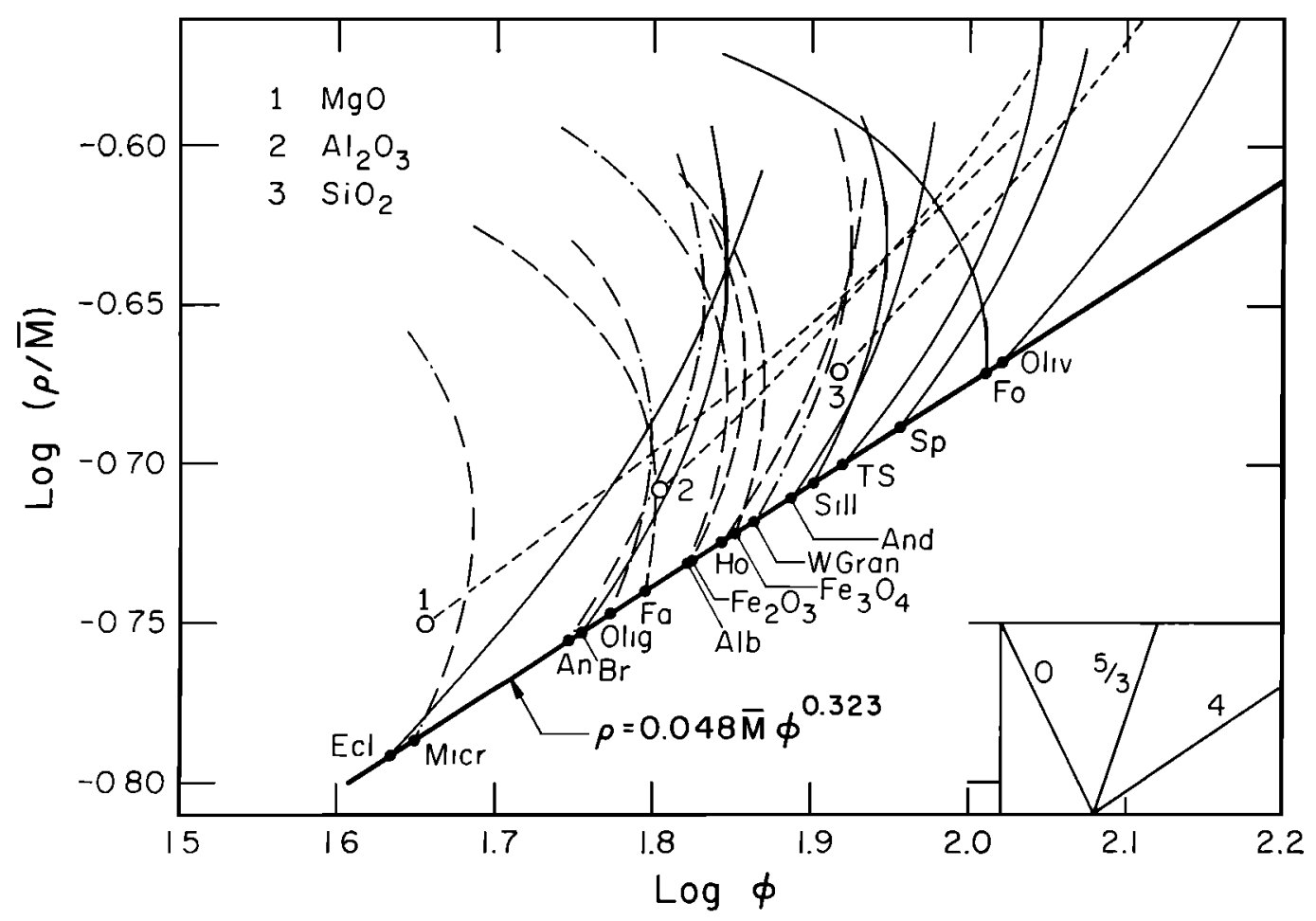

Fig. 1. Log $(\rho /\langle M\rangle)-\log \Phi$ plot of adiabats derived using equation 5 . Straight line is seismic equation of state line, equation 5 . Short-dashed curves, oxides; long-dashed curves, iron-rich compounds; dash-dot curves, rocks containing feldspars; solid curves, others listed in Tables 1 and 2. Abbreviations are identified in Table 1. Inset: lines with slopes corresponding to $d K / d P=0,5 / 3$, and 4 , as labeled. 
values of $K_{0}^{\prime}$ range from 1.05 to 3.0 (excluding enstatite, see later section), whereas the revised values range from 2.74 to 3.45 .

Some independent arguments can be made to further justify the above results. In fact, it may be noted that since the shock-wave data, in effect, determine relations between $\Phi_{0}$ and $\rho_{0}$ and $K_{0}^{\prime}$ and $\rho_{0}$ (or $\Phi_{0}$ ), then either the seismic equation of state (a relation between $\Phi_{0}$ and $\rho_{0}$ ) or any other acceptable criterion, such as arguments on the magnitude of $\Phi_{0}$ or $K_{0}^{\prime}$, could be used as an additional constraint. That an additional constraint is required was pointed out by D. L. Anderson and Kanamori [1968]. Arguments are given below on the magnitudes of both $K_{0}^{\prime}$ and $\Phi_{0}$.

Very low, negative, or rapidly fluctuating values of $d K / d P$ in minerals are usually only observed in association with the collapse of porous material, during phase changes, or at low pressures in some glasses [e.g., Manghnani et al., 1968; Fritz and Thurston, 1970]. Since glasses do not have a highly ordered crystal structure, and the other two cases involve the disruption of an ordered structure, these examples do not give any reason to expect anomalous behavior of $d K / d P$ over a large pressure range in materials with well defined structures. Further, laboratory measurements of $K_{0}^{\prime}$ for the low-pressure phases of dense minerals usually yield values in the range 4.0 to 5.4 [e.g., $O . L$. Anderson et al., 1968]. The present results, based on the revised seismic equation of state, seem to accord with the conjecture that $d K / d P$ of the high-pressure phases at zero pressure are less than $d K / d P$ of the low-pressure phases, and should tend smoothly, and perhaps monotonically, toward the Thomas-Fermi limit at high pressures. They are also consistent with the observation [O.L. Anderson et al., 1968] that high-density minerals of a given mean atomic weight have lower values for $d K / d P$ than low-density minerals. There is one more shred of evidence bearing on the $d K / d P$ of high-pressure phases of silicates. D. L. Anderson and Jordan [1970] estimated the zeropressure properties of the lower mantle from seismic data, and obtained a $d K / d P$ of 3.3. This

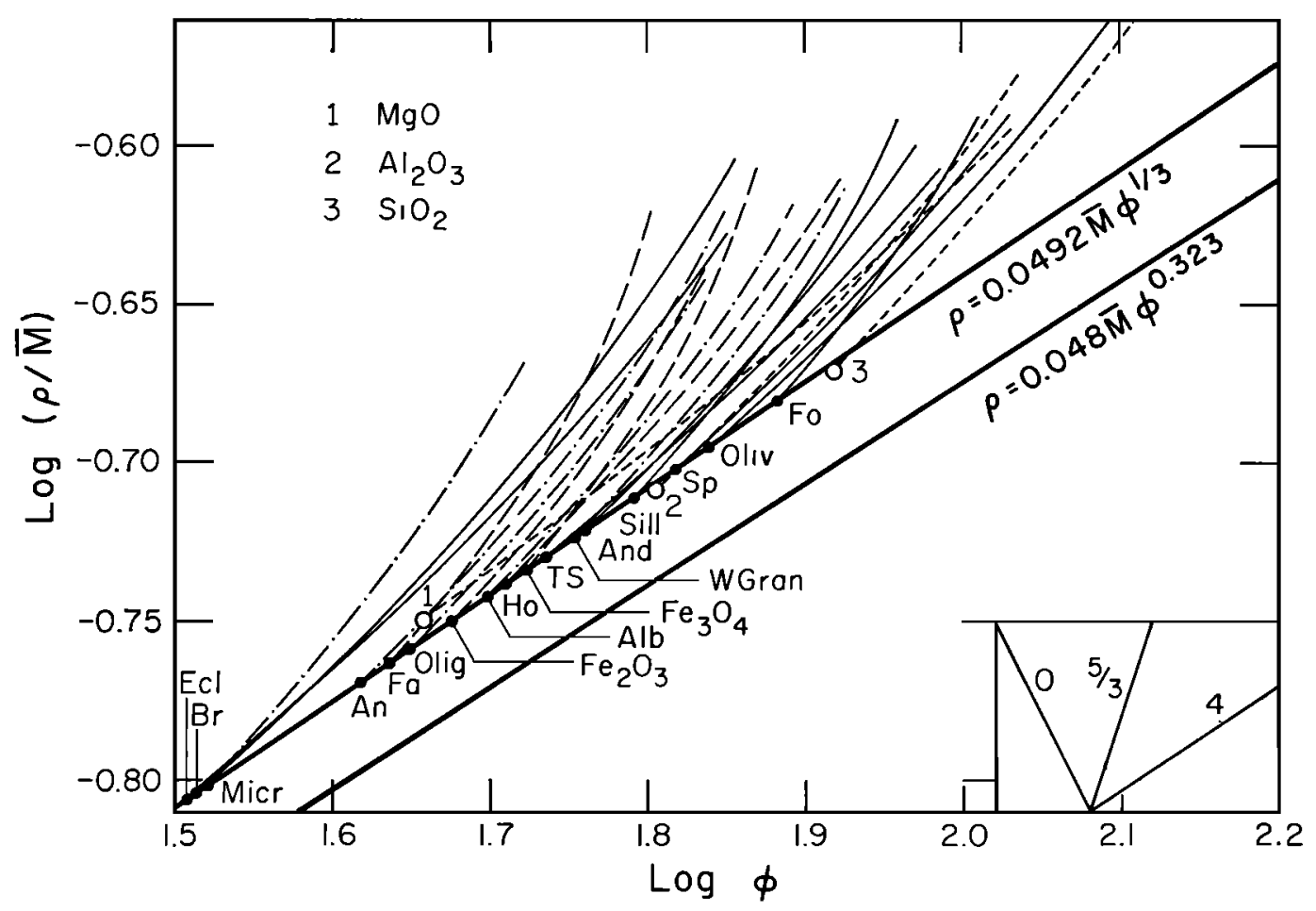

Fig. 2. As in Figure 1 for adiabats derived using equation 6. Solid straight line is revised seismic equation of state line, equation 6. Solid straight line of equation 5 is also shown. 
value is appropriate for a temperature of the order of $1600^{\circ} \mathrm{C}$, and would be lower at room temperature. Of the minerals studied in this paper olivinite and Twin Sister's dunite are the most pertinent for the lower mantle, and they have $d K / d P$ of 3.35 and 3.45 , respectively.

Before discussing other consequences of the use of the revised seismic equation of state, it should be pointed out that the rapid decrease of $d K / d P$ with pressure, which is seen especially in some of the results of Ahrens et al. [1969], is due in part to an undesirable char- acteristic of the Birch-Murnaghan equation. In a few cases, this was further aggravated by another artifice of the calculation. These points will be discussed in the next section.

Further effects of the revision of the seismic equation of state are to reduce the zero-pressure densities, usually by about 3 to $5 \%$, and to reduce $\Phi_{0}$ by $20 \%$ or more. In Table 2 the old and new densities and $\Phi$ 's are compared to the $\rho$ and $\Phi$ obtained by taking the molar average of $V$ and $\Phi$ of the component oxides of each substance. The densities are close to or slightly

TABLE 2. Comparison of Original and Revised $\rho_{0}$ and $\Phi_{0}$ with Those of the Isochemical Mixture of Oxides, and Proposed Crystal Structures and Densities of High-Pressure Phases

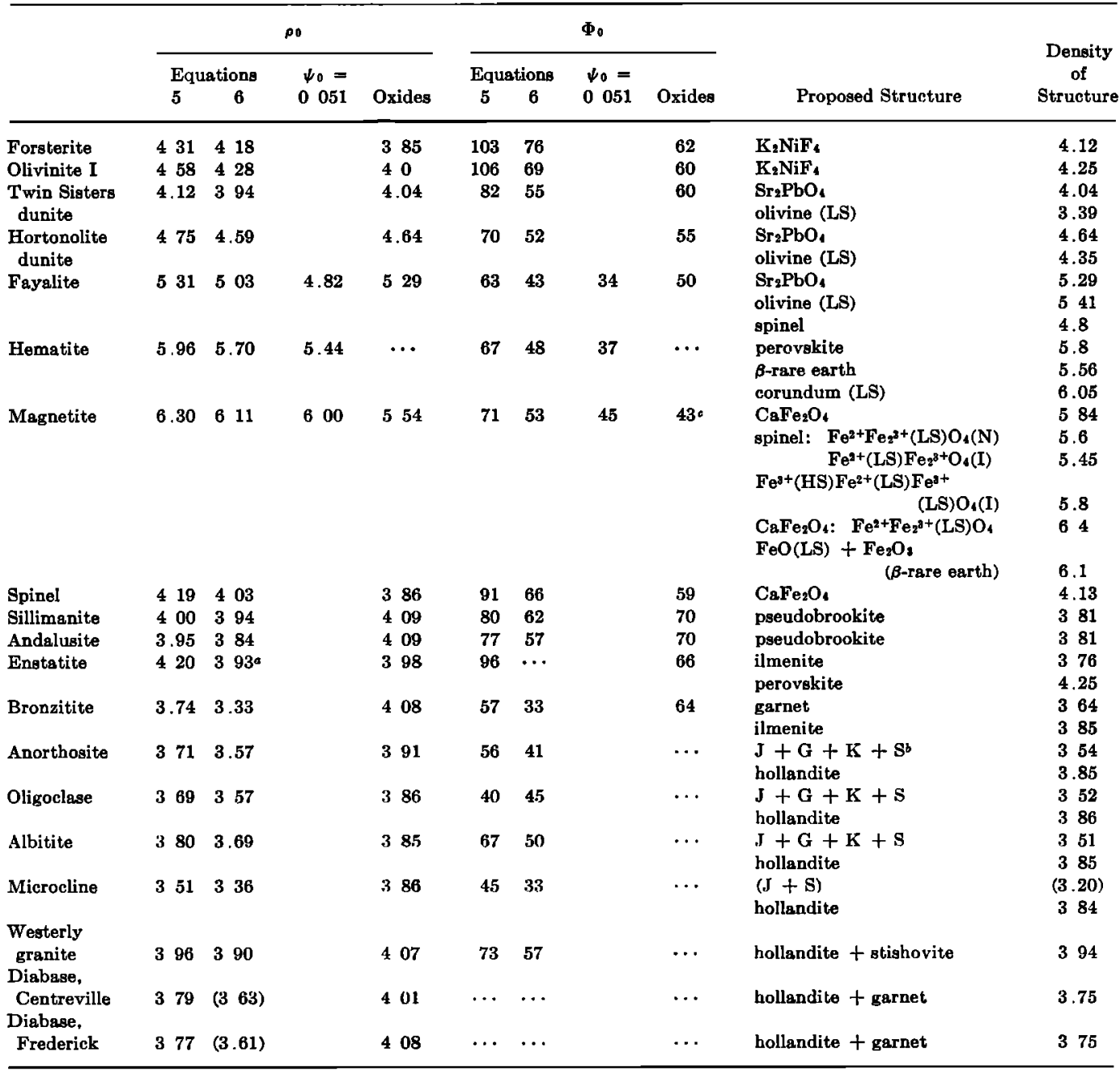

a Hugoniot.

${ }^{b} \mathrm{~J}=$ jadeite, $\mathrm{G}=$ grossular, $\mathrm{K}=$ kyanite, $\mathrm{S}=$ atishovite.

- Uses $\Phi_{0}\left(\mathrm{Fe}_{2} \mathrm{O}_{3}\right)=48$. 
greater than the 'mixed oxide' densities, as has been predicted on the basis of high-pressure static experiments on related compounds [e.g., Ringwood, 1969] (see also later discussion). In addition, the new $\Phi$ 's are close to the mixedoxide $\Phi$ 's, which is in accord with the suggestion made by $D$. L. Anderson [1969] that $\Phi$ could be estimated from that of the component oxides. This result is a consequence of constraining $\Phi$ and $\rho$ to lie on a line passing through the $\mathrm{MgO}$, $\mathrm{Al}_{2} \mathrm{O}_{3}$, and $\mathrm{SiO}_{2}$ points (Figure 2). Since these are the main components of most of the compounds considered, and since the densities are close to the mixed-oxide densities, $\Phi$ is constrained to be close to the mixed-oxide $\Phi$. Thus the use of the revised seismic equation of state is approximately equivalent to the hypothesis of the molar additivity of $\Phi[D . L$. Anderson, 1969].

The iron-rich compounds show systematically different behavior-in Figure 2 we see that $K^{\prime}$ is systematically lower for $\mathrm{Fe}_{2} \mathrm{O}_{3}, \mathrm{Fe}_{3} \mathrm{O}_{4}$, and fayalite. Exceptional behavior might be expected, since the $\Phi-\rho$ point for $\mathrm{FeO}$ (Table 1) apparently does not line up with the other oxides in Figure 2, and since it has been noted [D. L. Anderson, 1969] that the parameter $\Psi_{0}=\rho_{0} \Phi_{0}^{-1 / 3} /\langle M\rangle$ (cf. equation 6) increases with iron content. To allow for this, the iron-rich compounds were re-analyzed using $\Phi_{0}=0.0510$ (corresponding to roughly 70 wt $\% \mathrm{FeO}$ ), and the results are given in Table $1 . K_{0}^{\prime}$ is greater, and $\rho_{0}$ and $\Phi_{0}$ are less than previously. For fayalite, $\rho_{0}$ and $\Phi_{0}$ now seem to be anomalously low compared to the mixed-oxide values. The same may be true of $\mathrm{Fe}_{2} \mathrm{O}_{3}$, but $\mathrm{Fe}_{3} \mathrm{O}_{4}$ seems not unreasonable. Since decisive tests are difficult, considerable uncertainty must still attach to the iron-rich compounds.

\section{Effect of the Birch-Murnaghan Equation}

Consider the functional form of $d K / d P$ yielded by the Birch-Murnaghan equation. Differentiating (1), we get

$\frac{d K}{d P}=\frac{1}{3}\left[\frac{\left(49 x^{2}-25\right)-\xi\left(81 x^{4}-98 x^{2}+25\right)}{\left(7 x^{2}-5\right)-\xi\left(x^{2}-1\right)\left(9 x^{2}-5\right)}\right]$

The zero-pressure $(x=1)$ value is $K_{0}^{\prime}=$ $4-4 / 3 \xi$. Note that if $\xi=0$, (8) gives a highpressure $(x=\infty)$ limit of $7 / 3$, whereas if $\xi \neq 0$, the high-pressure limit is 3 . Figure 3 shows $d K / d P$ plotted against $x$ for several values of $\xi$. For $\xi=0\left(K_{0}^{\prime}=4\right), d K / d P$ decreases monotonically toward the high-pressure limit. For $\xi<0\left(K_{0}^{\prime}>4\right), d K / d P$ again decreases monotonically toward the high-pressure limit of 3 , but for $\xi>0\left(K_{0}^{\prime}<4\right)$ a singularity occurs for some value of $x>1$. In the latter case $d K / d P$ first decreases to minus infinity before changing sign and approaching the high-pressure limit. For $K_{0}^{\prime}=2$, for instance, $d K / d P$ becomes zero at about $x=1.08$, i.e., about $15 \%$ compression. Since it is found that $K_{0}^{\prime}<4$ for many of the materials analyzed here, it is evident that the Birch-Murnaghan equation must be used with caution. If $K_{0}^{\prime}$ is found to be less than 4, then the Birch-Murnaghan equation will be physically reasonable only within a restricted pressure range.

This singular behavior of the Birch-Murnaghan equation is not usually a problem. It arises

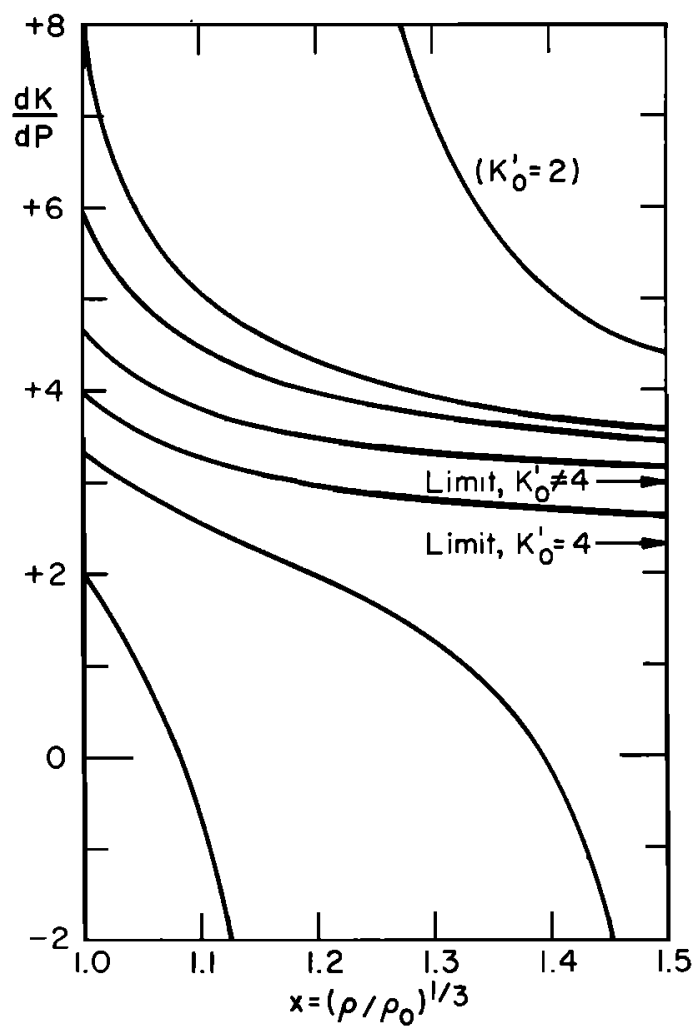

Fig. 3. $d K / d P$ derived from Birch-Murnaghan curve, equation 8 , versus compression, for various starting values $K_{a}^{\prime}=(d K / d P)_{e=1}$. 
here because the uncertainty of the zero-pressure density is reflected in large uncertainties in the other equation-of-state parameters. Alternative equations have recently been proposed that specifically have the property that $d K / d P$ approaches the high-pressure limit smoothly [Keane, 1954; O. L. Anderson, 1968; Fritz and Thurston, 1970].

For some of the substances with the lowest $K_{0}^{\prime}$ in Figure 1, the anomalous results have apparently been exaggerated by an additional effect. Ahrens et al. [1969] calculated the Grüneisen ratio from the formula

$$
\gamma=\gamma_{0} \rho_{0} / \rho
$$

where $\gamma_{0}$ was taken as the zero-pressure Dugdale-Macdonald value, which, from (4), is

$$
\begin{aligned}
\gamma_{0} & =\frac{3}{2}-\frac{2}{3} \xi \\
& =\frac{1}{2}\left(K_{0}^{\prime}-1\right)
\end{aligned}
$$

When $K_{0}^{\prime}$ is small, $\gamma$ can be unreasonably small, and in some such cases $\gamma$ was arbitrarily set equal to 1 . This has the effect of further decreasing the adiabatic value of $K_{0}^{\prime}$. The affected substances are forsterite, fayalite, oligoclase, albitite, and microcline. It is clear that $K_{0}^{\prime}$ must have been low in spite of this effect, and that many of the other substances still had very low values of $K_{0}^{\prime}$.

\section{InfERred Crystal Structures of High-Pressure Phases}

Because of the slightly lower $\rho_{0}$ obtained with the use of the revised seismic equation of state, the possible crystal structures of the high-pressure phases must be reconsidered. Table 2 compares the old and new $\rho_{0}$ and $\Phi_{0}$ to the mixed-oxide densities and $\Phi$ 's, and lists the suggested structures, together with their densities. As noted earlier, the densities are close to, or slightly greater than, the mixed-oxide densities. Because of the use of the revised seismic equation of state, the same systematic behavior can now be seen in $\Phi_{0}$ (see earlier discussion). Since the possible structures were discussed in detail by Ahrens et al. [1969], they will be discussed here only as the interpretation differs from theirs. The variety of arguments that may be used to determine likely crystal structures, in particular the estimation of the density of the structure (Table 2) from the systematics of isostructural compounds discussed more fully by Ahrens et al. [1969] and, for example, by Reid and Ringwood [1969].

Olivine group. Although the inferred densities of Twin Sisters dunite, Hortonolite dunite, and fayalite are slightly below the strontium plumbate structure densities, especially for fayalite, they are still comparable, and the fact that density, $\Phi_{0}$, and $K_{0}^{\prime}$ all change systematically with iron content suggests that these three substances are in the same structure. In contrast, for forsterite and olivinite I, $\rho_{0}$ and $\Phi_{0}$ are higher and $K_{0}^{\prime}$ is lower than would be expected from the above trends, so that the closer packed $\mathrm{K}_{2} \mathrm{NiF}_{4}$ structure is favored for both of these. The concordance obtained between the forsterite and olivinite I (Table 2 and Figure 2) is in striking contrast to the earlier results (Figure 1), and encourages both the above interpretation and the use of the revised seismic equation of state. A further consideration is that the low iron-content olivines do not transform from the olivine to the spinel phase, but transform into a distortion of this phase, the $\beta-\mathrm{Mg}_{2} \mathrm{SiO}_{4}$ structure [Ringwood, 1969]. Possibly, anomalous behavior could be expected at the higher pressure transformation from spinel (or $\beta-\mathrm{Mg}_{2} \mathrm{SiO}_{4}$ ) to the 'post-spinel' phases being considered here. It is not clear why the olivinite and Twin Sisters dunite should behave differently since they have similar iron contents, but the reaction kinetics may be sensitive to small differences in the sample porosities [Ahrens et al., 1969].

The 'low-spin' (LS) state structures in Table 2 will be discussed below in conjunction with the other high-iron content compounds.

Hematite, magnetite, spinel. The perovskite structure density for $\mathrm{Fe}_{2} \mathrm{O}_{3}$ of $5.8 \mathrm{~g} / \mathrm{cm}^{8}$ is somewhat higher than the revised density of 5.7 $\mathrm{g} / \mathrm{cm}^{3}$, but may still be considered compatible. If allowance is made in the shock analysis for the higher iron content, however (see earlier discussion), the shock density of $5.44 \mathrm{~g} / \mathrm{cm}^{3}$ is considerably lower than the perovskite structure density. An alternative is the $\beta$-rare earth structure, which would give a density of about $5.56 \mathrm{~g} / \mathrm{cm}^{8}$ [Reid and Ringwood, 1969] which is quite compatible with the shock-wave results. By calculating the heat of formation, Gaffney and Ahrens [1970] showed that $\mathrm{Fe}_{2} \mathrm{O}_{3}$ would only be stable in the perovskite structure if the 
$\mathrm{Fe}^{3+}$ disproportionated into $\mathrm{Fe}^{2+}$ and $\mathrm{Fe}^{4+}$, and even this possibility was open to doubt. The $\beta$-rare earth structure thus appears to be a reasonable candidate for this phase.

The revised densities of spinel $\left(\mathrm{MgAl}_{2} \mathrm{O}_{4}\right)$ and magnetite $\left(\mathrm{Fe}_{3} \mathrm{O}_{4}\right)$ are still significantly higher than the mixed-oxide densities. For $\mathrm{MgAl}_{2} \mathrm{O}_{4}$ the calcium ferrite structure density of $4.13 \mathrm{~g} / \mathrm{cm}^{3}$ is close enough to the derived density of $4.03 \mathrm{~g} / \mathrm{cm}^{3}$ to be acceptable. If the correction to the seismic equation of state allowing for the iron content of $\mathrm{Fe}_{3} \mathrm{O}$ is made, the derived density of $6.0 \mathrm{~g} / \mathrm{cm}^{3}$ is much less than previously obtained $\left(6.3 \mathrm{~g} / \mathrm{cm}^{\mathrm{a}}\right)$, and it does not seem necessary to invoke disproportionation to metallic iron via $3 \mathrm{Fe}_{3} \mathrm{O}_{4}=\mathrm{Fe}+4$ $\mathrm{Fe}_{2} \mathrm{O}_{3}$. Either the calcium ferrite structure $(\approx 5.8$ $\mathrm{g} / \mathrm{cm}^{3}$ ) or disproportionation into $\mathrm{FeO}+\mathrm{Fe}_{2} \mathrm{O}_{3}$ (perovskite) $\left(\approx 5.9 \mathrm{~g} / \mathrm{cm}^{3}\right)$ would not be unreasonable, the latter possibility depending on the interpretation of the high-pressure hematite phase as perovskite.

Electronic spin transitions. It has been suggested [e.g., Strens, 1969] that at high pressures and/or in certain coordinations the $\mathrm{Fe}^{2+}$ or $\mathrm{Fe}^{8+}$ ions (or both) would change their electronic configuration to a low-spin state in which one or more of the unpaired electrons in a higher energy level reverts to a lower energy level to form a 'spin-pair' in that level, with an accompanying decrease in ionic radius. In 6-coordination with $\mathrm{O}^{2-}$, the $\mathrm{Fe}^{2+}$ ion has a 'high-spin' (HS) radius of $0.77 \mathrm{~A}$ and a low-spin (LS) radius of $0.61 \mathrm{~A}$. For $\mathrm{Fe}^{\mathrm{s+}}$ in 6-coordination these are $0.645 \mathrm{~A}$ (HS) and $0.55 \mathrm{~A}$ (LS) [Shannon and Prewitt, 1969]. The ionic volume changes are thus substantial. The transition to low spin is more favored in octahedral or square planar coordination, and less favored in tetrahedral or cubic eightfold coordination [Strens, 1969].

We have considered some possible phase changes of the iron-rich compounds that might involve spin transitions. The crystal structure may be unchanged during the transition, or the changed ratios of cation to anion radii may require an accompanying change in crystal structure.

The simplest structure to consider is hematite. The $\mathrm{Fe}^{8+}$ are in distorted octahedral coordination, so it is possible that the $\mathrm{Fe}^{\mathrm{a}+}$ could undergo a spin transition (Gaffney, private com- munication) while the corundum structure is retained. (Note that the $\mathrm{Fe}^{3+} \mathrm{LS}$ ionic radius of $0.55 \mathrm{~A}$ is very close to the $\mathrm{Al}^{3+}$ radius of 0.53 A.) However, the density $6.05 \mathrm{~g} / \mathrm{cm}^{3}$ of this phase is considerably higher than that inferred from the shock data, and so it does not seem a very likely possibility.

There are several possibilities for $\mathrm{Fe}_{3} \mathrm{O}_{4}$. At low pressure it has an inverse spinel structure, with the $\mathrm{Fe}^{2+}$ ions occupying one half of the octahedral sites and $\mathrm{Fe}^{3+}$ occupying the tetrahedral sites and the other one half of the octahedral sites. Thus either the $\mathrm{Fe}^{2+}$ or the $\mathrm{Fe}^{3+}$ occupying the octahedral sites, or both, could change to LS. Another possibility, much more likely, is to form a normal spinel with $\mathrm{Fe}^{8+}$ (LS) occupying all of the octahedral sites (the closely analogous $\mathrm{FeAl}_{2} \mathrm{O}_{4}$ is a normal spinel). The estimated densities of these structures are given in Table 2 . Only the density $5.8 \mathrm{~g} / \mathrm{cm}^{\mathrm{s}}$ of the inverse spinel with all octahedrally coordinated cations in the LS state approaches the shock density $6.0+\mathrm{g} / \mathrm{cm}^{3}$. Another possibility is a transition to the calcium ferrite structure coupled with a spin transition in the $\mathrm{Fe}^{3+}$ ions, which would occupy octahedral sites in this structure. The estimated density of this is 6.4 $\mathrm{g} / \mathrm{cm}^{\mathrm{s}}$, which is rather high. Then there are various possible dissociations with $\mathrm{FeO}$ (rocksalt, $\rho \approx 5.95$; rocksalt LS, $\rho \approx 7.8$ ) and $\mathrm{Fe}_{2} \mathrm{O}_{3}$ (corundum, $\rho=5.27 ; \beta$-rare earth, $\rho=5.56$; corundum LS, $\rho \approx 6.05$ ), of which the best possibilities seem to be $\mathrm{FeO}$ (LS) + $\mathrm{Fe}_{2} \mathrm{O}_{3}\left(\beta\right.$-rare earth; $\left.\rho \approx 6.1 \mathrm{~g} / \mathrm{cm}^{3}\right)$ and $\mathrm{FeO}$ (rocksalt) $+\mathrm{Fe}_{2} \mathrm{O}_{3}$ (corundum LS; $\rho \approx 6.0$ $\mathrm{g} / \mathrm{cm}^{3}$ ). It is thus possible that spin transitions could be involved in the $\mathrm{Fe}_{2} \mathrm{O}_{3}$ and $\mathrm{Fe}_{3} \mathrm{O}_{4}$ phase changes, with the $\mathrm{Fe}^{2+}$ transition being a little more likely, but the evidence is not very strong.

If spin transitions are important in the earth, they are most likely to involve the $\mathrm{Fe}^{2+}$ ion in an olivine- or pyroxene-type solid solution. Although the $\mathrm{Fe}^{2+}$ sites in the olivine structure are octahedral, it can be seen from Table 2 that the shock-wave results for the dunites and fayalite cannot be explained by a spin transition in the olivine structure, since the density change would be too large for fayalite, but very small for the magnesium-rich olivines. In the strontium plumbate structure the $\mathrm{Fe}^{2+}$ is coordinated to 6 oxygen ions at the corners of a trigonal prism. In this coordination the spin pairing will 
begin at a lower pressure and will be complete at a higher pressure than in octahedral coordination (Gaffney, private communication). For pyroxenes in the enstatite and ilmenite structures, but not perovskite, $\mathrm{Fe}^{\mathrm{a+}}$ occupies octahedral sites. Thus olivines or pyroxenes containing some iron could have their densities increased by a few per cent through a spin transition, but the present shock-wave evidence is not sufficient to resolve this.

In summary, it is possible that spin transitions are involved in some of the shock-wave transformations, but there is little suggestion that they would occur in a mantle environment. If they did, the density changes would be a few per cent.

Enstatite, bronzitite. The density $3.93 \mathrm{~g} / \mathrm{cm}^{3}$ obtained here for enstatite is derived from the zero-pressure density of the hugoniot, since the data are so scattered that the iterative method used to calculate the adiabat would not converge. The density is comparable to that of the mixed oxides, and is intermediate between the ilmenite and perovskite structure densities. From the calculated heat of formation, Gaffney and Ahrens [1969] concluded that enstatite could only be stable in the perovskite structure if its density were less than about $3.9 \mathrm{~g} / \mathrm{cm}^{3}$. While this is probably compatible with the shock data, it is considerably less than the inferred structure density. It is perhaps more reasonable that enstatite should be in the ilmenite structure.

The revised bronzitite density $3.33 \mathrm{~g} / \mathrm{cm}^{\mathrm{a}}$ is dramatically less than the $3.74 \mathrm{~g} / \mathrm{cm}^{3}$ inferred by Ahrens et al. [1970], and is in fact close to the initial (untransformed) density of bronzitite $\left(3.28 \mathrm{~g} / \mathrm{cm}^{3}\right)$. The value $1.086 \mathrm{Mb}$ of bulk modulus is close to the value $1.05 \mathrm{Mb}$ found by Kumazawa [1969] on a single-crystal sample of a bronzite orthopyroxene of density 3.34 $\mathrm{g} / \mathrm{cm}^{\mathrm{s}}$. Thus, the bronzitite is probably only partially converted to a high-pressure phase. This conclusion is supported by the considerable scatter in the data.

Sillimanite, andalusite. The shock densities 3.94 and $3.84 \mathrm{~g} / \mathrm{cm}^{3}$ are intermediate between the estimated density $3.81 \mathrm{~g} / \mathrm{cm}^{3}$ of $\mathrm{Al}_{2} \mathrm{SiO}_{5}$ in the pseudobrookite structure and the mixedoxide density $4.09 \mathrm{~g} / \mathrm{cm}^{3}$. There is some doubt whether disproportionation into oxides is possible within the time of the shock pulse, and the shock densities are closer to the pseudobrookite density, so this may be the favored structure. In this structure, both cations are octahedrally coordinated to oxygen.

Feldspars (microcline; albitite, $A b_{\mathrm{sa}} A n_{\mathrm{z}}$; oligoclase, $A b_{s 1} A n_{19}$; anorthosite, $A b_{s 1} A n_{49}+10 \%$ augite). Candidates for these high-pressure phases are the hollandite structure $(\sim 3.85$ $\mathrm{g} / \mathrm{cm}^{\mathrm{a}}$ ) or a disproportionation of the albite $\left(\mathrm{NaAlSi}_{3} \mathrm{O}_{3}\right)$ into jadeite + stishovite and of the anorthite $\left(\mathrm{CaAl}_{2} \mathrm{Si}_{2} \mathrm{O}_{8}\right)$ into grossular + kyanite + stishovite. The disproportionation of microcline, $\mathrm{KAlSi}_{8} \mathrm{O}_{8}$ (Table 2), is speculative, since $\mathrm{KAISi}_{2} \mathrm{O}_{8}$ is not known in the jadeite structure. The shock densities are intermediate, nearer the disproportionation densities than the hollandite densities. D. L. Anderson [1969] has suggested that the effect of calcium is to decrease the parameter $\Psi_{0}$ in the seismic equation of state. If sodium and potassium have the same effect, then the shock densities in Table 2 might be underestimates, but the anomalous results obtained from the original seismic equation of state [Ahrens et al., 1969] (see Figure 1) suggest that this cannot be taken too far.

Westerly granite (quartz $27.5 \%$, microcline $35.4 \%$, oligoclase $\left(A n_{90}\right) 31.4 \%$, mica $\left.3.2 \%\right)$. The shock density $3.90 \mathrm{~g} / \mathrm{cm}^{3}$ is still in good agreement with the estimated density $3.94 \mathrm{~g} / \mathrm{cm}^{\mathrm{a}}$ of a stishovite + hollandite mixture, and provides better evidence than the individual feldspar data that the feldspars have transformed to the hollandite structure.

Diabases (W1: augite $45 \%$, labradorite $45 \%$, microcline $3 \%$; Frederick: augite 45\%, olivine $1 \%$, labradorite $48 \%$, mica 1\%). The shock densities given in Table 2 are extrapolated from those of Ahrens et al. [1970] and D. L. Anderson and Kanamori [1968], who used a seismic equation of state intermediate between the former and the present one. Since the presence of some aluminum in a pyroxene composition enhances the transformation to a garnet structure [Ringwood, 1969], we might expect that the augite has transformed to the garnet structure, with a density $\sim 3.65 \mathrm{~g} / \mathrm{cm}^{3}$. If the labradorite transformed to the hollandite structure, the resulting density would be $\sim 3.75$ $\mathrm{g} / \mathrm{cm},{ }^{3}$ which is in fairly good agreement with the shock densities. (The presence of calcium may again mean that the shock densities are underestimated.) The hypothesis that the pyrox- 
cnes have not transformed to a denser phase [Ahrens et al., 1969] gives the densities 3.70 (W1) and $3.66(\mathrm{~F}) \mathrm{g} / \mathrm{cm}^{3}$, which are also compatible, but this alternative seems less attractive in view of the enstatite and bronzitite results. It is also possible that the augite transformed to the ilmenite structure, giving densities $\sim 3.85 \mathrm{~g} / \mathrm{cm}^{3}$, which are rather high.

Acknowledgment. The authors gratefully acknowledge helpful discussions with Edward Gaffney.

This research was supported by National Science Foundation grant GA-12703 and Defense Atomic Support Agency contract DASA 01-70-C-0021.

\section{REFERENCES}

Ahrens, T. J., Don L. Anderson, and A. E. Ringwood, Equations of state and crystal structures of high-pressure phases of shocked silicates and oxides, Rev. Geophys., 7, 667-707, 1969.

Al'tshuler, L. V., R. F. Trunin, and G. V. Simahov, Shock-wave compression of periclase and quartz and the composition of the earth's lower mantle, Bull. Acad. Sci. USSR, Geophys. Series, English trans. no. 10, 1-6, 1965.

Anderson, Don L., A seismic equation of state, Geophys. J., 13, 9-30, 1967.

Anderson, Don L., Bulk modulus-density systematics, J. Geophys. Res., 74, 3857-3864, 1969.

Anderson, Don L., and T. Jordan, The composition of the lower mantle, Phys. Earth Planet. Interiors, 3, 23-35, 1970.

Anderson, Don L., and H. Kanamori, Shock-wave equations of state of rocks and minerals, $J$. Geophys. Res., 78, 6477-6502, 1968.

Anderson, O. L., On the use of ultrasonic and shock-wave data to estimate compressions at extremely high pressures, Phys. Earth Planet. Interiors, 1, 169-176, 1968.

Anderson, O. L., E. Schreiber, R. C. Liebermann, and N. Soga, Some elastic constant data on minerals relevant to geophysics, Rev. Geophys., $6,491-525,1968$.

Clark, S. P., Jr., editor, Handbook of Physical Constants, Memoir 97, Geological Society of America, New York, 1966.

Fritz, T. C., and R. N. Thurston, Extrapolation formula for finding the volume of solids at high pressures, J. Geophys. Res., 75, 15571569, 1970.

Gaffney, E. S., and T. J. Ahrens, Stability of mantle minerals from lattice calculations and shock wave data, Phys. Earth Planet. Interiors, 3, 205-212, 1970.

Keane, A., An investigation of finite strain in an isotropic material subjected to hydrostatic pressure and its seismological applications, Aust. J. Phys., 7, 323-333, 1954.

Kumazawa, M., The elastic constants of singlecrystal orthopyroxene, J. Geophys. Res., 74, 5973-5980, 1969.

Manghnani, M. H., E. Schrieber, and N. Soga, Use of ultrasonic interferometry technique for studying elastic properties of rocks, J. Geophys. Res., 73, 824-826, 1968.

March, N. H., Equations of state of elements from the Thomas-Fermi theory, Proc. Phys. Soc. London, A, 68, 726-734, 1955.

McQueen, R. G., S. P. Marsh, and J. N. Fritz, Hugoniot equation of state of twelve rocks, J. Geophys. Res., 72, 4999-5036, 1967.

Reid, A. F., and A. E. Ringwood, High pressure scandium oxide and its place in the molar volume relationship of dense structures of $\mathrm{M}_{2} \mathrm{X}_{3}$ and $\mathrm{ABX}_{3}$ type, J. Geophys. Res., 74, 3238-3252, 1969.

Ringwood, A. E., Phase transformations in the mantle, Earth Planet. Sci. Lett., 5, 401-412, 1969.

Shannon, R. D., and C. T. Prewitt, Effective ionic radii in oxides and fluorides, Acta Cryst., $B 25,925-946,1969$.

Strens, R. G. J., The nature and geophysical importance of spin pairing in minerals of iron (II), in The Application of Modern Physics to the Earth and Planetary Interiors, edited by S. K. Runcorn, Wiley-Interscience, New York, 1969.

Thomsen, L. T., On the fourth-order anharmonic equation of state of solids, J. Phys. Chem. Soc., 31, 2003-2016, 1970.

Trunin, R. F., V. I. Gon'shakova, G. V. Simakov, and N. E. Galdin, A study of rocks under the high pressures and temperatures created by shock compression (in Russian), Izv. Acad. Sci., USSR, Phys. Solid Earth, no. 9, 1-12, 1965. (Also English trans., no. 9, 579-586, 1966.)

Wackerle, J., Shock-wave compression of quartz, J. Appl. Phys., 3S, 922, 1962.

Wang, C. Y., Constitution of the lower mantle as evidenced from shock wave data for some rocks, J. Geophys. Res., 79, 6459-6474, 1968.

(Received September 23, 1970; revised December 10, 1970.) 